\title{
Neoadjuvant immunotherapy leads to pathological responses in MMR-proficient and MMR-deficient early- stage colon cancers
}

Citation for published version (APA):

Chalabi, M., Fanchi, L. F., Dijkstra, K. K., van den Berg, J. G., Aalbers, A. G., Sikorska, K., Lopez-Yurda, M., Grootscholten, C., Beets, G. L., Snaebjornsson, P., Maas, M., Mertz, M., Veninga, V., Bounova, G., Broeks, A., Beets-Tan, R. G., de Wijkerslooth, T. R., van Lent, A. U., Marsman, H. A., ... Haanen, J. B. (2020). Neoadjuvant immunotherapy leads to pathological responses in MMR-proficient and MMRdeficient early-stage colon cancers. Nature Medicine, 26(4), 566-576. https://doi.org/10.1038/s41591-0200805-8

Document status and date:

Published: 01/04/2020

DOI:

10.1038/s41591-020-0805-8

Document Version:

Publisher's PDF, also known as Version of record

\section{Document license:}

Taverne

Please check the document version of this publication:

- A submitted manuscript is the version of the article upon submission and before peer-review. There can be important differences between the submitted version and the official published version of record.

People interested in the research are advised to contact the author for the final version of the publication, or visit the DOI to the publisher's website.

- The final author version and the galley proof are versions of the publication after peer review.

- The final published version features the final layout of the paper including the volume, issue and page numbers.

Link to publication

\footnotetext{
General rights rights.

- You may freely distribute the URL identifying the publication in the public portal. please follow below link for the End User Agreement:

www.umlib.nl/taverne-license

Take down policy

If you believe that this document breaches copyright please contact us at:

repository@maastrichtuniversity.nl

providing details and we will investigate your claim.
}

Copyright and moral rights for the publications made accessible in the public portal are retained by the authors and/or other copyright owners and it is a condition of accessing publications that users recognise and abide by the legal requirements associated with these

- Users may download and print one copy of any publication from the public portal for the purpose of private study or research.

- You may not further distribute the material or use it for any profit-making activity or commercial gain

If the publication is distributed under the terms of Article $25 \mathrm{fa}$ of the Dutch Copyright Act, indicated by the "Taverne" license above, 


\title{
Multicentre study of short-course radiotherapy, systemic therapy and resection/ablation for stage IV rectal cancer
}

\author{
E. N. D. Kok ${ }^{1}$ (i), K. Havenga ${ }^{3}$, P. J. Tanis ${ }^{2}$, J. H. W. de Wilt ${ }^{4}$, J. Hagendoorn ${ }^{5}$, F. P. Peters ${ }^{6}$, J. Buijsen ${ }^{7}$, \\ H. J. T. Rutten ${ }^{8}$ and K. F. D. Kuhlmann ${ }^{1}$, on behalf of the Dutch Stage IV Rectal Cancer Group* \\ ${ }^{1}$ Department of Surgical Oncology, Netherlands Cancer Institute, ${ }^{2}$ Department of Surgery, Amsterdam UMC, University of Amsterdam, Amsterdam, \\ ${ }^{3}$ Department of Surgery, University of Groningen, Groningen, ${ }^{4}$ Department of Surgery, Radboud University Medical Centre, Nijmegen, ${ }^{5}$ Department \\ of Surgery, University Medical Centre Utrecht, Utrecht, ${ }^{6}$ Department of Radiation Oncology, Leiden University Medical Centre, Leiden, ${ }^{7}$ Department \\ of Radiation Oncology, Maastro Clinic, Maastricht, ${ }^{8}$ Department of Surgery, Catharina Hospital, Eindhoven, the Netherlands \\ Correspondence to: Dr E. N. D. Kok, Department of Surgical Oncology, The Netherlands Cancer Institute - Antoni van Leeuwenhoek, Plesmanlaan 121, \\ 1066 CX Amsterdam, the Netherlands (e-mail: endkok@gmail.com or e.kok@nki.nl)
}

\begin{abstract}
Background: The optimal treatment sequence for patients with rectal cancer and synchronous liver metastases remains unclear. The aim of this study was to evaluate the feasibility and effectiveness of short-course pelvic radiotherapy $(5 \times 5 \mathrm{~Gy})$ followed by systemic therapy and local treatment of all tumour sites in patients with potentially curable stage IV rectal cancer in daily practice.

Methods: This was a retrospective study performed in eight tertiary referral centres in the Netherlands. Patients aged 18 years or above with rectal cancer and potentially resectable liver \pm extrahepatic metastases, treated between 2010 and 2015, were eligible. Main outcomes included full completion of treatment schedule, symptom control and survival.

Results: In total, 169 patients were included with a median follow-up of 49.5 (95 pr cent c.i. 43.6 to 55.6) months. The completion rate for the entire treatment schedule was 65.7 per cent. Three-year progression-free survival and overall survival (OS) rates were 24.2 (95 per cent c.i. 16.6 to 31.6) and 48.8 (40.4 to 57.2) per cent respectively. Median OS of patients who responded well and completed the treatment schedule was 51.5 months, compared with $\mathbf{1 5 . 1}$ months for patients who did not complete the treatment $(P<0.001)$. Adequate symptom control of the primary tumour was achieved in 87.0 per cent of all patients.

Conclusion: Multimodal treatment leads to relief of symptoms in most patients, and is associated with good survival rates in those able to complete the schedule.

[Correction added on 12 February 2020, after first online publication: the Conclusion has been reworded for clarity]

* Other members of the Dutch Stage IV Rectal Cancer Group are co-authors of this article and can be found under the heading Collaborators

Presented to the 38th Congress of the European Society of Surgical Oncology, Budapest, Hungary, October 2018; published in abstract form as Eur 7 Surg Oncol 2019; 45: e9

Paper accepted 4 October 2019

Published online 3 February 2020 in Wiley Online Library (www.bjs.co.uk). DOI: 10.1002/bjs.11418
\end{abstract}

\section{Introduction}

Curative treatment of stage IV rectal cancer is challenging and up to 80 per cent of patients have unresectable liver metastases at diagnosis ${ }^{1}$. Previous studies ${ }^{2,3}$ have shown that systemic therapy can downsize the metastases with subsequent conversion to resectable or ablatable disease. Nevertheless, radical resection of multiple tumour sites remains challenging in patients with metastatic disease ${ }^{4}$. In the setting of synchronous metastases, the rectal tumour is often locally advanced. Traditionally, the preferred treatment is long-course chemoradiotherapy including 5 -fluorouracil or capecitabine as radiation sensitizer, with limited effect on distant metastases ${ }^{5,6}$. Consequently, the metastatic disease is left untreated for a significant period of time.

To minimize treatment delay, a new treatment schedule was introduced that combined radiotherapy of the primary tumour with a timely and adequate dose of systemic therapy to address the distant disease. This schedule consisted of preoperative short-course radiotherapy $(5 \times 5 \mathrm{~Gy})$, followed by six cycles of capecitabine-oxaliplatinbevacizumab (CAPOX-B), with the intention of subsequent surgical resection or ablation of all tumour sites $^{7}$. In a phase II single-arm study ${ }^{7}, 50$ patients with rectal cancer and resectable or ablatable liver and/or lung 
metastases underwent this treatment schedule. Eventually, 36 patients (72 per cent) underwent radical surgical treatment with 2-year recurrence-free and overall survival rates of 64 and 80 per cent respectively.

After completion of this so-called M1 study, multiple centres in the Netherlands implemented this treatment schedule in routine daily practice, as it effectively combines local control of the rectal tumour with a timely start of systemic therapy. Although the original study ${ }^{7}$ only included patients with treatable and limited metastatic disease, less strict eligibility criteria are used in daily practice. The aim of the present study was to evaluate the feasibility and effectiveness of this treatment schedule in stage IV rectal cancer patients in daily practice.

\section{Methods}

This was a retrospective study in eight centres in the Netherlands: Amsterdam University Medical Centre, Catharina Hospital Eindhoven, University Medical Centre Groningen, Leiden University Medical Centre, Maastricht University Medical Centre, Netherlands Cancer Institute (Amsterdam), Radboud University Medical Centre (Nijmegen) and University Medical Centre Utrecht. Patients with a diagnosis of synchronous metastasized rectal cancer were identified from institutional databases and registrations between January 2010 and December 2015.

Patients were eligible if rectal cancer with (potentially) curable liver \pm extrahepatic metastases was confirmed histologically and they were scheduled for the multimodality treatment, consisting of $5 \times 5$ Gy pelvic radiotherapy followed by systemic therapy and subsequent surgery, with or without other local treatment modalities. Simultaneous lung or distant lymph node metastases were accepted as long as treatment with curative intent was deemed possible after systemic therapy. Standard diagnostic investigation consisted of pelvic MRI for local staging of the rectal tumour and CT of the chest, abdomen and pelvis to detect distant metastases. All patients were discussed in a multidisciplinary meeting with (intervention) radiologists, and medical, radiation and surgical oncologists. Clinical data of eligible patients were collected from medical records and anonymized.

This study was approved by the institutional review board (METC17.1695/M17CRM).

\section{Neoadjuvant treatment and reassessment}

Patients with significant signs of obstruction at diagnosis received a diverting stoma. Neoadjuvant short-course radiotherapy $(5 \times 5 \mathrm{~Gy})$ was given to the primary tumour, mesorectum and regional lymph nodes. Systemic therapy started approximately 2 weeks after the last fraction of radiation. The choice of systemic therapy regimen was at the discretion of the local team. After three cycles of systemic therapy, radiological evaluation of response was performed using CT and MRI. In each participating centre a multidisciplinary team decided on the next optimal treatment step: continuation of systemic treatment, staged or simultaneous local treatment of primary tumour and/or distant metastases, or palliative treatment.

\section{Surgery and histopathology}

After completion of neoadjuvant treatment, the multidisciplinary team reviewed the resectability of the primary tumour and metastases. The optimal sequence of surgical treatment and type of surgical procedure with or without other local treatment modalities were tailored to the individual patient. Other local treatment modalities included radiofrequency ablation (RFA) and stereotactic radiotherapy. Primary tumour resection was performed by partial or total mesorectal excision ${ }^{8}$. The choice of surgical procedure and the use of a diverting stoma were at the discretion of the local surgeon. Treatment of extrahepatic metastases included pulmonary metastasectomy, pulmonary RFA, stereotactic radiotherapy of the lung and lymph node resection. In patients with complete response of the primary tumour and/or the metastases to neoadjuvant treatment, a watch-and-wait approach was sometimes chosen ${ }^{9}$. After surgical resection of all tumour sites, no adjuvant therapy was given. Histopathological evaluation of the specimen was performed by the local pathologist. Downstaging of the primary tumour was evaluated, comparing the baseline c $\mathrm{T}$ status with the (y)p T status.

\section{Outcomes}

The main outcomes were completion of the entire treatment schedule, pathological response and overall survival (OS). Ancillary outcomes were treatment-related toxicity, surgical complications, symptom control of the primary tumour and progression-free survival (PFS). Completion of the treatment schedule was defined as neoadjuvant short-course radiotherapy, at least two cycles of systemic therapy and subsequent local treatment of all tumour sites. Treatment-related toxicity was registered using the US National Cancer Institute Common Terminology Criteria for Adverse Events version 4.0 ${ }^{10}$. Radiotherapy-related toxicity was classified as acute and late toxicity, defined as toxicities within or after 3 months. Surgical complications for both liver and rectal surgery were graded using 


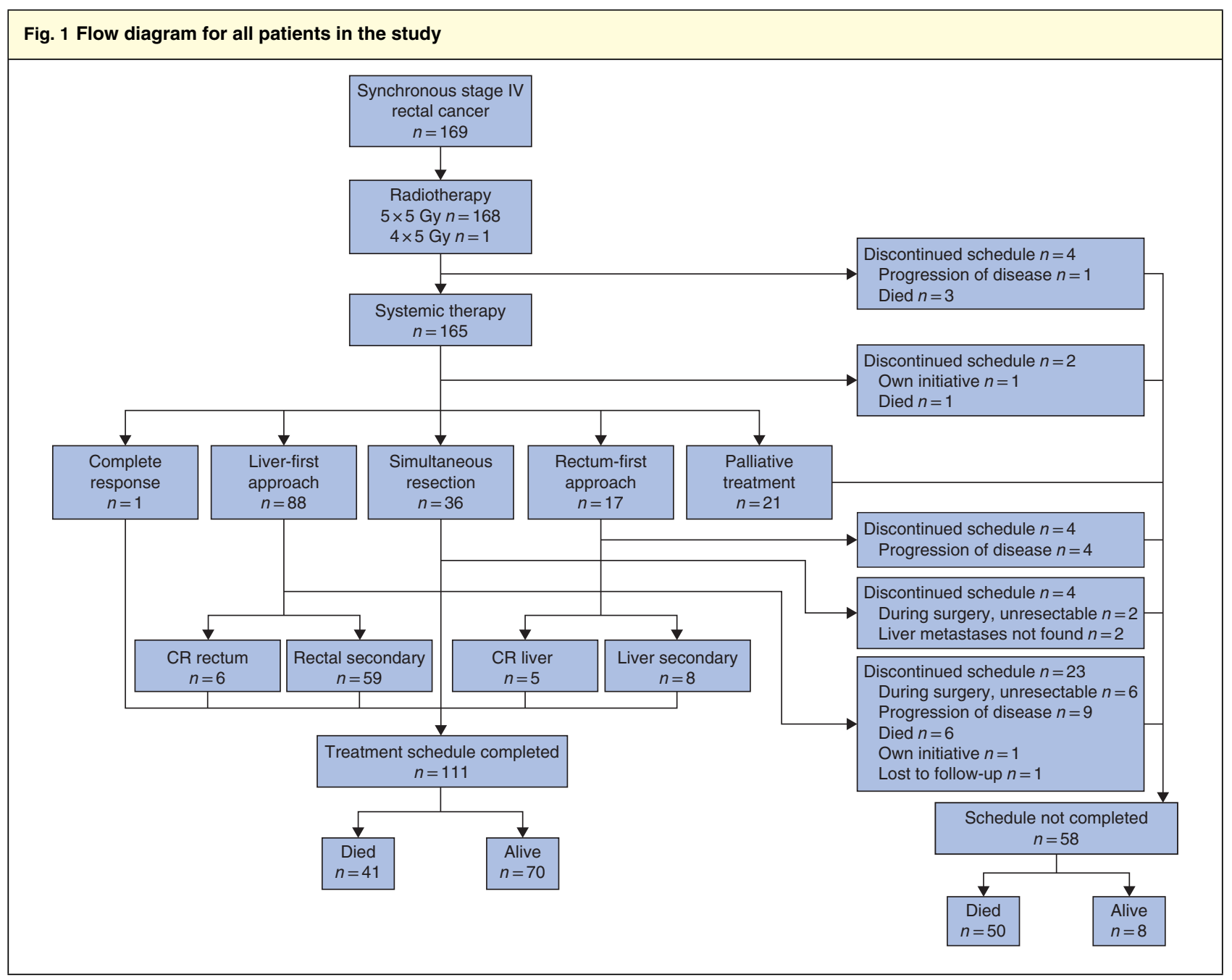

$\mathrm{CR}$, complete response.

the Dindo-Clavien classification ${ }^{11}$. Tumour response evaluation was assessed using the RECIST (Response Evaluation Criteria In Solid Tumours) criteria version 1.0 $0^{12}$. PFS was calculated from the first day of radiotherapy to the first evidence of recurrence (local, regional or metastatic) or until death. OS was calculated from the first day of radiotherapy until death or last documented follow-up.

\section{Statistical analysis}

All analyses were performed using SPSS ${ }^{\circledR}$ version 24.0 (IBM, Armonk, New York, USA). Patients and treatment characteristics are presented as percentages, medians with ranges or medians with 95 per cent confidence intervals. Categorical variables were compared using the $\chi^{2}$ test, and continuous variables with the Mann-Whitney $U$ test. OS and PFS were calculated using Kaplan-Meier curves. The association of completing the treatment schedule with OS was analysed using an extended Cox proportional hazards model, in which treatment completion was used as the time-dependent co-variable to avoid immortal time bias. The log rank test was used to compare survival probabilities between subgroups. Univariable and multivariable Cox regression analyses were performed to identify predictors of survival. A binary logistic regression model was used to identify prognostic factors of treatment completion. All variables with significance of $P \leq 0.200$ in univariable analysis were entered in the multivariable analysis. $P<0.050$ (two-sided) was regarded as statistically significant.

\section{Results}

Between January 2010 and December 2015, 169 patients with potentially resectable or ablatable stage IV rectal 


\begin{tabular}{|c|c|}
\hline & No. of patients ${ }^{\star}(n=169)$ \\
\hline Age at start of treatment (years) $\dagger$ & $63(32-83)$ \\
\hline Sex ratio (M : F) & $109: 60$ \\
\hline \multicolumn{2}{|l|}{ WHO performance status } \\
\hline 0 & $128(75 \cdot 7)$ \\
\hline 1 & $33(19.5)$ \\
\hline 2 & $8(4 \cdot 7)$ \\
\hline \multicolumn{2}{|l|}{ Clinical tumour and node status } \\
\hline T2 No & $2(1 \cdot 2)$ \\
\hline T2 N1-2 & $11(6 \cdot 5)$ \\
\hline T3NO & $10(5 \cdot 9)$ \\
\hline T3N1-2 & $117(69 \cdot 2)$ \\
\hline $\mathrm{T} 4 \mathrm{~N} 1-2$ & $29(17 \cdot 2)$ \\
\hline Mesorectal fascia involvement & $75(44.4)$ \\
\hline \multicolumn{2}{|l|}{ Location of primary rectal cancer } \\
\hline Low $(0-5 \mathrm{~cm})$ & $67(39.6)$ \\
\hline Middle $(5-10 \mathrm{~cm})$ & $76(45 \cdot 0)$ \\
\hline High $(10-15 \mathrm{~cm})$ & $24(14 \cdot 2)$ \\
\hline Unknown & $2(1 \cdot 2)$ \\
\hline \multicolumn{2}{|l|}{ Metastatic site } \\
\hline Liver only & $130(76 \cdot 9)$ \\
\hline Liver and lung & $19(11 \cdot 2)$ \\
\hline Liver and distant lymph nodes & $19(11 \cdot 2)$ \\
\hline Liver, lung and distant lymph nodes & $1(0.6)$ \\
\hline No. of liver metastases $\dagger$ & $3(1-20)$ \\
\hline \multicolumn{2}{|l|}{ Location of liver metastases } \\
\hline Unilobar & $95(56 \cdot 2)$ \\
\hline Bilobar & $74(43 \cdot 8)$ \\
\hline Diameter of largest metastasis $(\mathrm{cm}) \dagger$ & $3 \cdot 0(0 \cdot 8-22 \cdot 1)$ \\
\hline
\end{tabular}

*With percentages in parentheses unless indicated otherwise; †values are median (range).

cancer fulfilled the criteria and started the treatment schedule (Fig. 1). Patient and treatment characteristics are shown in Tables 1 and 2 respectively. In 70 patients ( 41.4 per cent), all tumour sites were considered surgically amenable for local treatment before any neoadjuvant treatment. Neoadjuvant $5 \times 5$ Gy radiotherapy was completed in 168 patients; the other patient received only four fractions of 5 Gy owing to bowel toxicity (perforation). Overall, 94.1 per cent of all patients received between three and eight cycles of systemic therapy. Systemic therapy consisted of capecitabine and oxaliplatin (CAPOX); capecitabine, oxaliplatin and bevacizumab (CAPOX-B); capecitabine and bevacizumab (CAP-B); fluorouracil, oxaliplatin and folinic acid (FOLFOX), fluorouracil, oxaliplatin, folinic acid and bevacizumab (FOLFOX-B) or capecitabine monotherapy. Median follow-up was 49.5 (95 per cent c.i. 43.6 to $55 \cdot 6$ ) months.

\begin{tabular}{|c|c|}
\hline & $\begin{array}{l}\text { No. of patients } \\
\quad(n=169)\end{array}$ \\
\hline \multicolumn{2}{|l|}{ Diverting stoma } \\
\hline Before all treatment & $26(15 \cdot 4)$ \\
\hline During neoadjuvant treatment & $14(8 \cdot 3)$ \\
\hline \multicolumn{2}{|l|}{ Radiotherapy } \\
\hline $5 \times 5$ Gy & $168(99 \cdot 4)$ \\
\hline $4 \times 5$ Gy & $1(0 \cdot 6)$ \\
\hline Chemotherapy & $n=165$ \\
\hline CAPOX & $41(24.9)$ \\
\hline CAPOX-B & $109(66 \cdot 1)$ \\
\hline FOLFOX & $5(3 \cdot 0)$ \\
\hline FOLFOX-B & $5(3 \cdot 0)$ \\
\hline CAP & $4(2 \cdot 4)$ \\
\hline CAP-B & $1(0 \cdot 6)$ \\
\hline Total no. of administered cycles $\dagger$ & $6(1-14)$ \\
\hline $1-3$ & $48(29 \cdot 1)$ \\
\hline $4-6$ & $102(61 \cdot 8)$ \\
\hline$\geq 7$ & $15(9 \cdot 1)$ \\
\hline Rectal resection $\neq$ & $n=112$ \\
\hline Low anterior resection & $74(66 \cdot 1)$ \\
\hline Hartmann procedure & $13(11 \cdot 6)$ \\
\hline Abdominoperineal resection & $25(22 \cdot 3)$ \\
\hline Liver treatment & $n=132$ \\
\hline Liver resection & $83(62.9)$ \\
\hline RFA alone & $13(9 \cdot 8)$ \\
\hline Resection + RFA & $34(25 \cdot 8)$ \\
\hline Radiotherapy & $2(1.5)$ \\
\hline \multicolumn{2}{|l|}{ Treatment of extrahepatic metastases } \\
\hline \multicolumn{2}{|l|}{ Lung } \\
\hline Metastasectomy & $6(3.6)$ \\
\hline Pulmonary RFA & $3(1 \cdot 8)$ \\
\hline Radiotherapy & $2(1 \cdot 2)$ \\
\hline Lymph node resection & $2(1 \cdot 2)$ \\
\hline Combined lymph node and rectal resection & $4(2 \cdot 4)$ \\
\hline Rectal radiotherapy expanded for lymph node & $2(1 \cdot 2)$ \\
\hline \multicolumn{2}{|l|}{ Length of hospital stay (days) $\dagger$} \\
\hline Rectal resection & $8(3-29)$ \\
\hline Liver resection & $7(1-62)$ \\
\hline Simultaneous resection & $14(5-57)$ \\
\hline
\end{tabular}

*With percentages in parentheses unless indicated otherwise; †values are median (range). $\ddagger$ Includes 36 local treatment procedures performed during simultaneous resections. CAP, capecitabine; OX, oxaliplatin; B, bevacizumab; FOLFOX, 5 -fluorouracil, folinic acid and oxaliplatin; RFA, radiofrequency ablation.

\section{Completion of entire treatment schedule}

In total, 111 patients ( 65.7 per cent) completed the entire treatment schedule. After neoadjuvant treatment, 88 patients received a liver-first approach, and in 17 primary tumour resection was performed first. Simultaneous 
Table 3 Anatomical location of progression of disease during and after completing the treatment schedule

\begin{tabular}{|lcc|}
\hline Anatomical location & $\begin{array}{c}\text { During treatment } \\
\text { schedule }\end{array}$ & $\begin{array}{c}\text { After treatment } \\
\text { schedule }\end{array}$ \\
Liver & 25 & 23 \\
Lung & 3 & 13 \\
Liver and lung & 8 & 15 \\
Liver and rectum (local recurrence) & 3 & 2 \\
Lung and rectum (local recurrence) & 0 & 2 \\
Other & 9 & 14 \\
\hline
\end{tabular}

surgery of the primary tumour and liver metastases was performed in 36 patients. A complete response at all tumour sites after neoadjuvant treatment was seen in one patient, and a watch-and-wait approach was applied (Fig. 1).

In multivariable logistic regression, the number of liver metastases (hazard ratio 0.82, 95 per cent c.i. 0.66 to $0.94 ; P=0.004)$ was the only significant predictor for completion of the entire treatment schedule. Of the 58 patients who were not able to complete the treatment schedule, 24 (41 per cent) received palliative systemic treatment, 19 (33 per cent) refrained from active treatment, four ( 7 per cent) received palliative radiotherapy, ten (17 per cent) died and one ( 2 per cent) was lost to follow up.

\section{Progression-free and overall survival}

Forty-eight patients had progressive disease during treatment and 69 after completing the entire treatment schedule. Progression of disease was observed most frequently in the liver (Table 3). Seven patients developed local recurrence after rectal surgery. Of the
Fig. 2 Kaplan-Meier analysis of overall survival for the whole cohort, patients who completed the treatment schedule, and those who did not

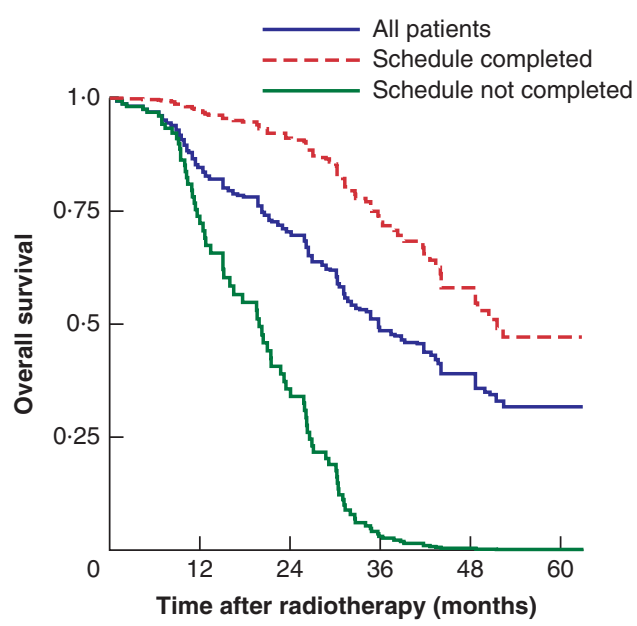

No. at risk

$\begin{array}{lcccccc}\text { All patients } & 169 & 134 & 93 & 59 & 35 & 17 \\ \begin{array}{r}\text { Schedule } \\ \text { completed }\end{array} & 111 & 103 & 79 & 58 & 35 & 17 \\ \begin{array}{r}\begin{array}{r}\text { Schedule not } \\ \text { completed }\end{array} \\ 5\end{array} & 38 & 31 & 14 & 1 & 0 & 0\end{array}$

$P<0.001$ (log rank test).

48 patients who showed progression during the treatment schedule, seven were able to complete the entire schedule and 41 were not. The 1-, 3- and 5-year PFS rates for all patients were 59.3 (95 per cent c.i. 51.6 to $66 \cdot 9), 24.2(16 \cdot 6$ to $31 \cdot 6)$ and $17 \cdot 1$ (9.6 to $24 \cdot 5)$ per cent respectively.

Median OS for all patients was 35.7 (range 1.0-88.4) months. The 1-, 3- and 5-year OS rates were 85.2 (95 per cent c.i. 79.7 to $90 \cdot 7), 48 \cdot 8(40.4$ to $57 \cdot 2)$ and $31 \cdot 1(22.8$ to

Table 4 Univariable and multivariable analyses for overall survival

\begin{tabular}{|c|c|c|c|c|}
\hline & \multicolumn{2}{|c|}{ Univariable analysis } & \multicolumn{2}{|c|}{ Multivariable analysis } \\
\hline & Hazard ratio & $\boldsymbol{P}$ & Hazard ratio & $\boldsymbol{P}$ \\
\hline Age at diagnosis (continuous) & $0.99(0.97,1.01)$ & 0.351 & & \\
\hline Sex (M versus F) & $1 \cdot 18(0 \cdot 76,1 \cdot 84)$ & 0.453 & & \\
\hline WHO performance status (2 versus $0-1$ ) & $1.06(0.72,1.55)$ & 0.782 & & \\
\hline \multicolumn{5}{|l|}{ No. of liver metastases } \\
\hline Continuous & $1.12(1.04,1.21)$ & 0.003 & $1.11(1.02,1.20)$ & 0.011 \\
\hline$>4$ versus $\leq 4$ & $1.76(1.13,2 \cdot 76)$ & 0.013 & & \\
\hline cT category (IV versus II-III) & $1.47(0.95,2.27)$ & 0.086 & $1.30(0.83,2.03)$ & 0.252 \\
\hline cN category (II versus $0-\mathrm{I}$ ) & $1.23(0.86,1 \cdot 75)$ & 0.253 & & \\
\hline Extrahepatic disease (yes versus no) & $1.37(0.85,0.20)$ & 0.200 & $1.24(0.77,2 \cdot 01)$ & 0.379 \\
\hline
\end{tabular}




\begin{tabular}{|c|c|c|c|}
\hline & No. of events & No. of patients with events & Total no. of patients \\
\hline \multicolumn{4}{|l|}{ Radiotherapy-related toxicity } \\
\hline Grade 3-4 & & 11 & 169 \\
\hline Acute & 9 & & \\
\hline Late & 2 & & \\
\hline Grade 5 & & 1 & 169 \\
\hline Acute & 1 & & \\
\hline Late & 0 & & \\
\hline \multicolumn{4}{|l|}{ Chemotherapy-related toxicity* } \\
\hline Grade 3-4 & & 45 & 165 \\
\hline Gastrointestinal & 31 & & \\
\hline Vascular & 12 & & \\
\hline Neurological & 7 & & \\
\hline Dermatological & 7 & & \\
\hline Haematological & 5 & & \\
\hline Cardiological & 2 & & \\
\hline Infection & 2 & & \\
\hline Grade 5 & 0 & 0 & 165 \\
\hline Unknown toxicity & & 22 & 165 \\
\hline \multicolumn{4}{|l|}{ Surgical complications } \\
\hline Grade III-IV, staged rectal resection† & & 14 & 112 \\
\hline Ileus/gastroparesis & 4 & & \\
\hline Anastomotic leakage & 4 & & \\
\hline Presacral abscess & 3 & & \\
\hline Wound dehiscence & 2 & & \\
\hline Other & 3 & & \\
\hline Grade III-IV, staged liver treatment $\uparrow$ & & 16 & 132 \\
\hline \multicolumn{4}{|l|}{ Infection/abscess } \\
\hline Abdominal & 6 & & \\
\hline Thorax & 4 & & \\
\hline Wound & 2 & & \\
\hline Bleeding & 3 & & \\
\hline Bile duct perforation or stenosis & 3 & & \\
\hline Other & 4 & & \\
\hline Grade V, liver treatment & & 3 & 132 \\
\hline Acute coronary syndrome & 3 & & \\
\hline Grade III-IV, simultaneous resection $\dagger$ & & 16 & 36 \\
\hline \multicolumn{4}{|l|}{ Infection/abscess } \\
\hline Abdominal & 6 & & \\
\hline Thorax & 6 & & \\
\hline Wound & 3 & & \\
\hline lleus/gastroparesis & 4 & & \\
\hline Wound dehiscence & 3 & & \\
\hline Other & 4 & & \\
\hline
\end{tabular}

*Some patients had more than one toxicity; $\dagger$ some patients had more than one complication.

39.9) per cent respectively (Fig. 2). The median OS for the 111 patients who completed the entire treatment schedule was 51.5 months, compared with 15.1 months in patients who did not complete the treatment $(P<0 \cdot 001)$. The 3and 5 -year OS rates for patients who completed the entire treatment schedule were $73 \cdot 6(64 \cdot 1$ to $83 \cdot 1)$ and $46 \cdot 8(34 \cdot 8$ to 58.7) respectively.

In multivariable analysis, the number of liver metastases (hazard ratio $1 \cdot 11 ; 95$ per cent c.i. 1.02 to $1 \cdot 20 ; P=0 \cdot 011$ ) was associated with decreased OS (Table 4). 


\section{Evaluation of radiological and pathological responses}

Complete radiological and endoscopic response of the rectal tumour was observed in 11 of 165 patients (6.7 per cent), allowing a watch-and-wait approach. Five of these patients had recurrence of the rectal tumour within 6 months and underwent rectal resection. In six patients, no recurrence was observed during follow-up (median follow-up 26.6 months). A partial response was observed in $49 \cdot 1$ per cent of patients. A radiological complete response of the liver was observed in five patients $(3.0$ per cent).

Clear margins at rectal surgery (R0) were accomplished in 99 (88.4 per cent) of the 112 patients who had a rectal resection, including 14 patients $(12.5$ per cent) with a pathological complete response. Pathological downstaging of the primary tumour was seen in 38 patients $(33.9$ per cent). Resection margins of the liver specimen were involved (R1) in 11 (10.3 per cent) of the 107 patients undergoing surgical resection of liver metastatses. A pathological complete response of the liver was reported in 15 patients ( 14.0 per cent).

\section{Toxicity and morbidity}

Grade 3-4 radiotherapy-related toxicity was observed in 11 of the 169 patients ( 6.5 per cent) (Table 5). One patient died within 1 month after radiotherapy from rectal bleeding. Chemotherapy-related grade 3-4 toxicity was observed in 45 patients (27.3 per cent). Gastrointestinal complaints and pulmonary embolism were reported most frequently.

Severe surgical complications (grade III-IV) were observed after rectal resection in 14 patients $(12.5$ per cent). The most frequent complications were ileus and anastomotic leakage. Grade III-IV complications after liver treatment occurred in 16 of 132 patients $(13.7$ per cent). Twelve of the 16 patients suffered from infection in the abdomen/thorax or of the wound. Within 30 days of liver surgery, three patients ( 2.3 per cent) died from acute coronary syndrome. After simultaneous resection, 16 of the 36 patients ( 44 per cent) experienced grade III-IV complications. The most common complications were abdominal, pulmonary and wound infection.

\section{Control of symptoms from the primary tumour}

Despite short-course radiotherapy, 35 patients experienced rectal complaints during the treatment schedule. The most reported complaints were pain, obstruction and rectal bleeding. Of all patients, 16 (8.5 per cent) received pharmacological treatment, 14 ( 8.2 per cent) required a diverting stoma during systemic treatment, and in four patients ( 2.4 per cent) rectal surgery was performed earlier than planned. In the remaining 131 patients (79.4 per cent), the treatment schedule provided local symptom control during follow-up in both curative and palliative settings.

\section{Discussion}

This evaluation of clinical practice shows that subsequent local treatment of all tumour sites after multimodal neoadjuvant therapy was achieved in the majority of patients, with tolerable morbidity and mortality. The number of liver metastases at diagnosis appeared to be the only predictor of treatment completion and survival. In the initial prospective M1 study ${ }^{7,13}, 80$ per cent of patients received local treatment at all tumour sites, with a 5 -year OS rate of 38 per cent, whereas in the present study these numbers were lower. In the initial trial, only patients with limited metastatic disease, who were considered treatable with curative intent at baseline, were included. In the present study, less than half of the patients had resectable metastases at baseline and the resectability of the metastases in most patients was highly dependent on the response of the systemic treatment.

In locally advanced rectal cancer, short-course radiotherapy with subsequent systemic therapy can be an alternative for long-course chemoradiotherapy. A large randomized study $^{14}$ compared short-course radiotherapy combined with three cycles of FOLFOX4 with long-course chemoradiotherapy in patients with locally advanced rectal cancer (cT4 or fixed cT3). No significant difference was observed in local efficacy between the treatments. A different study ${ }^{15}$ with a similar design found improved pathological tumour downstaging and better disease-free and metastasis-free survival in patients treated with short-course radiotherapy plus chemotherapy. In the present study, complete pathological response of the primary tumour was observed in 12.5 per cent, omitting surgical treatment in six patients, and a partial response in 49.1 per cent.

Symptom control is important in patients with rectal cancer. Short-course pelvic radiotherapy has been shown to be an effective palliative treatment modality in patients with symptomatic rectal cancer ${ }^{16,17}$. Many clinicians, however, are hesitant to use short-course radiotherapy in patients with locally advanced disease because of the perceived risk of providing less optimal local control compared with that obtained with chemoradiotherapy. In the present study, adequate symptomatic local control of the primary tumour was achieved in the majority of the patients. This confirms that short-course radiotherapy followed by systemic chemotherapy is an effective and safe treatment in stage IV rectal cancer, in both the curative and palliative setting. 
Systemic chemotherapy plays a significant role in downstaging liver metastases and eradication of microscopic disease. Earlier studies ${ }^{18,19}$ showed that induction chemotherapy can convert initially unresectable liver metastases to resectable disease. In the present study, 99 patients $(58.6$ per cent) had potentially or borderline resectable/ablatable liver metastases at the time of diagnosis. Of these patients, $60 \cdot 1$ per cent had a partial response after systemic treatment, enabling curative liver treatment. This confirms that systemic treatment can downsize metastases to resectable disease, yet the optimal regimen has not been defined. Currently, a Dutch multicentre randomized phase 3 trial (CAIRO5) is underway that compares multiple systemic treatment regimens in patients with colorectal cancer and initially unresectable liver-only metastases (NCT02162563) ${ }^{20}$. The estimated study completion date is the end of 2020 .

An alternative treatment for stage IV rectal cancer has been published previously ${ }^{21-23}$. Patients received chemotherapy followed by a liver-first approach. After liver surgery, (chemo)radiotherapy was administered with subsequent primary tumour resection. Ninety of the 129 patients (69.8 per cent) completed the protocol, of whom ten had a (near) complete response of the primary tumour. A disadvantage of this approach is that the duration of treatment is longer compared with the schedule in the present study. Moreover, with this approach a simultaneous resection is not feasible because of the treatment sequence.

\section{Collaborators}

Members of the Dutch Stage IV Rectal Cancer Group include: G. L. Beets, A. G. J. Aalbers, N. F. M. Kok, T. J. M. Ruers, C. B. H. A. Kobus, S. V. Siemons, C. Grootscholten, L. G. H. Dewit, J. G. van den Berg and I. Zavrakidis (Netherlands Cancer Institute); K. P. de Jong, G. A. P. Hospers and A. Karrenbeld (University Medical Centre Groningen, University of Groningen); E. D. Geijsen and C. J. A. Punt (Amsterdam UMC, University of Amsterdam); H. Rutten and S. Radema (Radboud University Medical Centre, Nijmegen); M. P. W. Intven and J. M. L. Roodhart (University Medical Centre Utrecht); F. Holman and E. Kapiteijn (Leiden University Medical Centre); J. Melenhorst (Maastricht University Medical Centre); J. S. Cnossen and G.-J. M. Creemers (Catharina Hospital, Eindhoven).

\section{Disclosure}

The authors declare no conflict of interest.

\section{References}

1 Adam R, Delvart V, Pascal G, Valeanu A, Castaing D, Azoulay D et al. Rescue surgery for unresectable colorectal liver metastases downstaged by chemotherapy: a model to predict long-term survival. Ann Surg 2004; 240: 644.

2 Lam VWT, Spiro C, Laurence JM, Johnston E, Hollands MJ, Pleass HCC et al. A systematic review of clinical response and survival outcomes of downsizing systemic chemotherapy and rescue liver surgery in patients with initially unresectable colorectal liver metastases. Ann Surg Oncol 2012; 19: 1292-1301.

3 Devaud N, Kanji ZS, Dhani N, Grant RC, Shoushtari H, Serrano PE et al. Liver resection after chemotherapy and tumour downsizing in patients with initially unresectable colorectal cancer liver metastases. HPB (Oxford) 2014; 16: 475-480.

4 Reddy SK, Pawlik TM, Zorzi D, Gleisner AL, Ribero D, Assumpcao L et al. Simultaneous resections of colorectal cancer and synchronous liver metastases: a multi-institutional analysis. Ann Surg Oncol 2007; 14: 3481-3491.

5 Sauer R, Becker H, Hohenberger W, Rödel C, Wittekind C, Fietkau $\mathrm{R}$ et al. Preoperative versus postoperative chemoradiotherapy for rectal cancer. N Engl 7 Med 2004; 351: $1731-1740$.

6 Hofheinz RD, Wenz F, Post S, Matzdorff A, Laechelt S, Hartmann JT et al. Chemoradiotherapy with capecitabine versus fluorouracil for locally advanced rectal cancer: a randomised, multicentre, non-inferiority, phase 3 trial. Lancet Oncol 2012; 13: 579-588.

7 van Dijk TH, Tamas K, Beukema JC, Beets GL, Gelderblom AJ, de Jong KP et al. Evaluation of short-course radiotherapy followed by neoadjuvant bevacizumab, capecitabine, and oxaliplatin and subsequent radical surgical treatment in primary stage IV rectal cancer. Ann Oncol 2013; 24: $1762-1769$.

8 Glynne-Jones R, Wyrwicz L, Tiret E, Brown G, Rödel C, Cervantes A et al. Rectal cancer: ESMO Clinical Practice Guidelines for diagnosis, treatment and follow-up. Ann Oncol 2017; 28(Suppl 4): iv22-iv40.

9 Renehan AG, Malcomson L, Emsley R, Gollins S, Maw A, Myint AS et al. Watch-and-wait approach versus surgical resection after chemoradiotherapy for patients with rectal cancer (the OnCoRe project): a propensity-score matched cohort analysis. Lancet Oncol 2016; 17: 174-183.

10 US Department of Health and Human Services, National Institutes of Health, National Cancer Institute. Common Terminology Criteria for Adverse Events (CTCAE); 2010. https://evs.nci.nih.gov/ftp1/CTCAE/CTCAE_4.03/ CTCAE_4.03_2010-06-14_QuickReference_5x7.pdf [accessed 18 September 2018].

11 Dindo D, Demartines N, Clavien P-A. Classification of surgical complications: a new proposal with evaluation in a cohort of 6336 patients and results of a survey. Ann Surg 2004; 240: 205-213.

12 Therasse P, Arbuck SG, Eisenhauer EA, Wanders J, Kaplan $\mathrm{RS}$, Rubinstein L et al. New guidelines to evaluate the 
response to treatment in solid tumors. European Organization for Research and Treatment of Cancer, National Cancer Institute of the United States, National Cancer Institute of Canada. 7 Natl Cancer Inst 2000; 92: 205-216.

13 Bisschop C, van Dijk TH, Beukema JC, Jansen RLH, Gelderblom H, de Jong KP et al. Short-course radiotherapy followed by neoadjuvant bevacizumab, capecitabine, and oxaliplatin and subsequent radical treatment in primary stage IV rectal cancer: long-term results of a phase II study. Ann Surg Oncol 2017; 24: 2632-2638.

14 Bujko K, Wyrwicz L, Rutkowski A, Malinowska M, Pietrzak L, Krynski J et al. Long-course oxaliplatin-based preoperative chemoradiation versus $5 \times 5$ Gy and consolidation chemotherapy for cT4 or fixed cT3 rectal cancer: results of a randomized phase III study. Ann Oncol 2016; 27: 834-842.

15 Markovina S, Youssef F, Roy A, Aggarwal S, Khwaja S, DeWees T et al. Improved metastasis- and disease-free survival with preoperative sequential short-course radiation therapy and FOLFOX chemotherapy for rectal cancer compared with neoadjuvant long-course chemoradiotherapy: results of a matched pair analysis. Int $\mathcal{Z}$ Radiat Oncol Biol Phys 2017; 99: 417-426.

16 Picardi V, Deodato F, Guido A, Giaccherini L, Macchia G, Frazzoni L et al. Palliative short-course radiation therapy in rectal cancer: a phase 2 study. Int 7 Radiat Oncol Biol Phys 2016; 95: 1184-1190.

17 Tyc-Szczepaniak D, Wyrwicz L, Kepka L, Michalski W, Olszyna-Serementa M, Palucki J et al. Palliative radiotherapy and chemotherapy instead of surgery in symptomatic rectal cancer with synchronous unresectable metastases: a phase II study. Ann Oncol 2013; 24: 2829-2834.
18 Wong R, Cunningham D, Barbachano Y, Saffery C, Valle J, Hickish T et al. A multicentre study of capecitabine, oxaliplatin plus bevacizumab as perioperative treatment of patients with poor-risk colorectal liver-only metastases not selected for upfront resection. Ann Oncol 2011; 22: 2042-2048.

19 Folprecht G, Gruenberger T, Bechstein WO, Raab HR, Lordick F, Hartmann JT et al. Tumour response and secondary resectability of colorectal liver metastases following neoadjuvant chemotherapy with cetuximab: the CELIM randomised phase 2 trial. Lancet Oncol 2010; 11: 38-47.

20 Huiskens J, van Gulik TM, van Lienden KP, Engelbrecht MR, Meijer GA, van Grieken NC et al. Treatment strategies in colorectal cancer patients with initially unresectable liver-only metastases, a study protocol of the randomised phase 3 CAIRO5 study of the Dutch Colorectal Cancer Group (DCCG). BMC Cancer 2015; 15: 365.

21 Verhoef C, van der Pool AEM, Nuyttens JJ, Planting AST, Eggermont AMM, de Wilt JHW. The 'liver-first approach' for patients with locally advanced rectal cancer and synchronous liver metastases. Dis Colon Rectum 2009; 52: 23-30.

22 Ayez N, Burger JW, van der Pool AE, Eggermont AM, Grunhagen DJ, de Wilt JH et al. Long-term results of the 'liver first' approach in patients with locally advanced rectal cancer and synchronous liver metastases. Dis Colon Rectum 2013; 56: 281-287.

23 Nierop PMH, Verseveld M, Galjart B, Rothbarth J, Nuyttens J, van Meerten E et al. The liver-first approach for locally advanced rectal cancer and synchronous liver metastases. Eur 7 Surg Oncol 2019; 45: 591-596. 